\title{
NKX2-1 expression as a prognostic marker in early-stage non-small-cell lung cancer
}

Jorge Moisés ${ }^{1}$, Alfons Navarro ${ }^{2}$, Sandra Santasusagna ${ }^{2}$, Nuria Viñolas ${ }^{3}$, Laureano Molins ${ }^{4}$, José Ramirez ${ }^{5}$, Jeisson Osorio ${ }^{1}$, Adela Saco ${ }^{5}$, Joan Josep Castellano ${ }^{2}$, Carmen Muñoz ${ }^{2}$, Sara Morales ${ }^{2}$, Mariano Monzó ${ }^{2 *}$ and Ramón María Marrades ${ }^{1 *}$

\begin{abstract}
Background: NKX2-1, a key molecule in lung development, is highly expressed in non-small cell lung cancer (NSCLC), particularly in lung adenocarcinoma (ADK), where it is a diagnostic marker. Studies of the prognostic role of NKX2-1 in NSCLC have reported contradictory findings. Two microRNAs (miRNAs) have been associated with NKX2-1: miR-365, which targets NKX2-1; and miR-33a, which is downstream of NKX2-1. We have examined the effect of NKX2-1, miR-365 and miR-33a on survival in a cohort of early-stage NSCLC patients and in sub-groups of patients classified according to the mutational status of TP53, KRAS, and EGFR.

Methods: mRNA and miRNA expression was determined using TaqMan assays in 110 early-stage NSCLC patients. TP53, KRAS, and EGFR mutations were assessed by Sanger sequencing.

Results: NKX2-1 expression was upregulated in never-smokers $(P=0.017)$, ADK $(P<0.0001)$ and patients with wild-type TP53 $(P=0.001)$. A negative correlation between NKX2-1 and miR-365 expression was found $(\rho=-0.287$; $P=0.003$ ) but there was no correlation between NKX2-1 and miR-33a expression. Overall survival (OS) was longer in patients with high expression of NKX2-1 than in those with low expression (80.8 vs 61.2 months $(P=0.035)$, while a trend towards longer OS was observed in patients with low miR-365 levels ( $P=0.07$ ). The impact of NKX2-1 on OS and DFS was higher in patients with neither TP53 nor KRAS mutations. Higher expression of NKX2-1 was related to higher OS (77.6 vs 54 months; $P=0.017$ ) and DFS (74.6 vs 57.7 months; $P=0.006$ ) compared to low expression. The association between NKX2-1 and OS and DFS was strengthened when the analysis was limited to patients with stage I disease ( $P=0.005$ and $P=0.003$ respectively).
\end{abstract}

Conclusions: NKX2-1 expression impacts prognosis in early-stage NSCLC patients, particularly in those with neither TP53 nor KRAS mutations.

Keywords: NKX2-1, microRNA, TP53, NSCLC, miR-365, miR-33a

\footnotetext{
*Correspondence: mmonzo@ub.edu; marrades@clinic.cat Jorge Moisés and Alfons Navarro equally contributed to this paper Mariano Monzó and Ramón María Marrades equally contributed as senior authors.

${ }^{2}$ Molecular Oncology and Embryology Laboratory, Human Anatomy Unit, School of Medicine, University of Barcelona, IDIBAPS, Casanova 143, 08036 Barcelona, Spain

${ }^{1}$ Department of Pneumology, Institut Clínic Respiratori (ICR), Hospital Clínic de Barcelona, University of Barcelona, IDIBAPS, CIBER de Enfermedades Respiratorias (CIBERES), Barcelona, Spain

Full list of author information is available at the end of the article
} 


\section{Background}

Lung cancer is the leading cause of cancer-related death in developed countries [1, 2]. In Europe 410,000 new cases of lung cancer and 353,000 related deaths were estimated to occur in 2012 [3]. In the most frequent type, non-small-cell lung cancer (NSCLC), more than 70\% of patients debut with locally advanced or metastatic disease [4]. In patients that present with early-stage disease, surgery alone or surgery followed by cisplatin-based adjuvant treatment is the first line of treatment. Although surgery is considered a curative treatment, $30-55 \%$ of patients will relapse during the first two years [5]. These data highlight the need to further investigate this disease and consolidate useful prognostic markers.

NK2 homeobox 1 (NKX2-1), also known as thyroid transcription factor-1 (TTF-1), is a key transcription factor that orchestrates the development of the lung, thyroid and forebrain in the embryonic period [6]. In adult lung tissue, NKX2-1 is expressed in conducting airways type II alveolar epithelial cells and in Clara cells and uniformly in the terminal respiratory unit [7]. NKX2-1 regulates surfactant protein transcription by directly binding to the promoter of SP-A [8], SP-B [9], SP-C [10], clara cell secretory protein (CCSP) [11], and T1< [12]. NKX2-1 is commonly used in clinical practice for the differential diagnosis of the adenocarcinoma (ADK) subtype of NSCLC $[13,14]$. More than $70 \%$ of ADK are positive for NKX2-1 by immunohistochemistry, independent of disease stage [15].

Most of the studies that have examined the role of NKX2-1 in oncogenesis have highlighted its role as tumor suppressor. NKX2-1 inhibits proliferation by inhibiting the embryonal proto-oncogene High Mobility Group At-Hook 2 (HMGA2) [16]. In addition, NKX2-1 inhibits cell motility and metastatic capacity through modification of intercellular junctions and cytoskeleton elements. It promotes the expression of E-Cadherin, Ocludin (OCLN) and CLN 1/18 [17]. It also inhibits epithelial-to-mesenchymal transition (EMT) by repressing transforming growth factor $\beta$ (TGF $\beta$ ), which produces an increase of E-Cadherin levels [18]. NKX2-1 also activates MYBPH synthesis, which inhibits actomyosin filaments, crucial elements in cell migration [19]. In addition, NKX2-1 regulates transcription of P53, a gene frequently lost or mutated in NSCLC patients [20, 21 . Reduced expression of NKX2-1 has been associated with initiation and progression of invasive mucinous lung ADK in patients harboring KRAS mutations [22].

MicroRNAs (miRNAs) are small non-coding RNAs (22-24 nucleotides in length) that regulate posttranscriptional processes via sequence-specific interactions with the 3' untranslated regions (UTR) of mRNA [23]. Two miRNAs have been associated with NKX2-1: miR-365 and miR-33a. Using an in silico method, Mu et al. identified and validated miR-365 as a miRNA that directly regulates NKX2-1 by binding to its 3'UTR and inhibiting its translation [24]. Interestingly, a feed-back signaling loop between miR-365 and TGF $\beta$ was described, illustrating that miR-365 participates in the NKX2-1 repression of TGF $\beta$ [24]. miR-33a, located downstream of NKX2-1, was previously shown to have cholesterol homeostasis regulatory activity and to bind to the 3'UTR of HMGA2. These data indicate that NKX2-1 upregulates miR-33a, which represses HMGA2 [25] and could inhibit EMT, thus controlling lung cancer metastasis [26].

The prognostic value of NKX2-1 expression is controversial. Although most studies report that lower expression of NKX2-1 is associated with shorter overall survival (OS) in NSCLC [27-30], others report an inverse prognostic correlation [31]. We hypothesized that miR-365a, NKX2-1 and miR-33a could work together to influence growth and differentiation of lung cancer cells and that the study of this axis could thus help to understand the discrepancies observed in the prognostic impact of NKX2-1. We have studied the expression of NKX2-1 and its associated miRNAs, miR-365 and miR-33a, in a cohort of 110 early-stage NSCLC patients and correlated our findings with overall survival (OS).

\section{Methods}

\section{Patient samples}

From June 2007 to November 2013, tumor tissue samples were prospectively collected from 110 adult patients diagnosed with stage I-II NSCLC who underwent complete surgical resection in our institution. All patients had Spanish ethnicity. Tissue samples were immediately immersed in RNALater ${ }^{\circ}$ (Ambion) and stored at $-80{ }^{\circ} \mathrm{C}$ until processing. Clinical data were recorded on admission: age, gender, smoking history, preoperative pulmonary function tests, chronic obstructive pulmonary disease (COPD), Eastern Cooperative Oncology Group (ECOG) performance status (PS), clinical and postoperative staging according to TNM 7th edition [32], type of surgical resection and pathological findings (histological subtype, and the presence of emphysema). Information regarding adjuvant treatment, relapse and clinical outcomes was also recorded. The mutational status of TP53 and K-RAS was assessed in all patients, and EGFR mutational status was assessed in ADK patients.

\section{RNA extraction and gene expression analysis}

Total RNA was isolated from frozen tissue using TriZol $^{\odot}$ Reagent (Life Technologies) according to the manufacturer's protocol. RNA from samples was quantified using a NanoDrop ND-1000 Spectrophotometer (Fisher Scientific, Madrid, Spain). 
cDNA was obtained from 500 ng of total RNA using the High Capacity cDNA Reverse Transcription Kit ${ }^{\oplus}$ (Life Technologies) as per manufacturer's protocol. NKX2-1 mRNA expression levels were quantified using a TaqMan Gene Expression assay (Hs00968940_m1) in a 7500 Real-Time PCR System (Life Technologies). Relative expression levels were calculated by $2^{-\Delta \Delta C t}$ method using $18 \mathrm{~S}$ as endogenous control.

\section{miRNA quantification}

miR-365 and miR-33a expression was analyzed using TaqMan MicroRNA Assay (Applied Biosystems) as previously described [33]. Relative quantification was calculated using $2^{-\Delta \Delta C t}$. Normalization was performed with miR-191 [34]. All experiments were performed in triplicate.

\section{TP53, K-RAS and EGFR mutation analysis}

PCR to identify TP53, K-RAS and EGFR mutations was performed on 50-ng DNA samples and the Sanger sequencing process was performed by STAB Vida (Caparica, Portugal). The mutation analysis for TP53 included the exons 5-8 and used the following primers: exon 5 forward(F) 5' - GTTTCTTTGCTGCCGTCTTC-3', 5 reverse (R) 5'-GAGCAATCAGTGAGGAATCAGA-3'; exon 6F 5'-AGAGACGACAGGGCTGGTT-3', 6R 5'-CT TAACCCCTCCTCCCAGAG-3'; exon 7F 5'-TTGCCAC AGGTCTCCCCAA-3', 7R 5'-AGGGGTCAGAGGCAA GCAGA-3'; exon 8F 5'-GGGACAGGTAGGACCTGA TTT-3', 8R 5'-TAACTGCACCCTTGGTCTCC-3'.

The mutation analysis for K-RAS included the codons 12 and 13 and used the following primers: F 5'TTA ACCTTATGTGTGACATGTTCTAA-3', R 5'-AGAATG GTCCTGCACCAGTAA-3'.

The mutation analysis for EGFR included the exons $18,19,20$ and 21 and used the following primers: exon 18 F 5'-GCATGGTGAGGGCTGAGGT-3', 18R 5'-TG CAAGGACTCTGGGCTCC-3'; exon 19 F 5'-TGCAT CGCTGGTAACATCCA-3', 19R 5'-GAAAAGGTGGGC CTGAGGTT-3'; exon 20F 5'-TCCTTCTGGCCACCA TGC-3', 20R 5'-TGGCTCCTTATCTCCCCTCC-3'; exon 21F 5'-ATGCAGAGCTTCTTCCCATGA-3', 21R 5'-CAGGAAAATGCTGGCTGACC-3'.

\section{TTF-1 immunohistochemistry staining}

IHC was performed on formalin-fixed, paraffinembedded tissue sections of 16 lung carcinomas and 3 normal lung controls from the Pathology Service of the Hospital Clinic of Barcelona after review by a thoracic pathologist. 4- $\mu \mathrm{m}$-thick transverse sections of formalinfixed, paraffin-embedded tissue were serially cut and mounted onto Dako Silanized Slides (S3003; Dako, Glostrup, Denmark). For antigen retrieval, the sections were manually immersed in Target Retrieval solution, high $\mathrm{pH}$ (Dako) and heated in a water bath at 95-99uC for $20 \mathrm{~min}$. Endogenous peroxidase activity was quenched by immersion in Dako Real Peroxidase-Blocking solution for $10 \mathrm{~min}$. The tissue sections were incubated with primary antibody against TTF1 (1:100, 8g7g3/1, DAKO, glostrop, Denmark). The slides were then washed in Tris- $\mathrm{HCl}$ and detected with horseradish peroxidase-conjugated anti-rabbit EnVision + kit (DAKO). Finally, sections were stained with hematoxylin. All slides were blindly scored by the same two pathologists. Nuclear staining of tumor cells was considered TTF1+. Tumors with completely no TTF1 expression in nuclei were de ned as TTF1 - .

\section{Statistical analyses}

The primary endpoint of the study was OS, defined as the time between surgery and death from any cause. KaplanMeier curves for OS were drawn and compared by means of a log-rank test. All factors with $P \leq 0.1$ in the univariate analysis were included in the Cox multivariate regression analyses for OS. Optimal cut-offs of NKX2-1 expression data for OS were assessed by means of maximally selected logrank statistics using the Maxstat package ( $\mathrm{R}$ statistical package, v. 2.8.1, Vienna, Austria) [35] and confirmed by the Kaplan-Meier test. Student T-Test or Mann-Whitney U test, as appropriate, were used for comparisons between two groups or ANOVA when more than two groups were compared. Pearson correlation was used to compare the NKX21 expression with its associated miRNAs. All statistical analyses were performed using PASW Statistics 21 (SPSS Inc.) and $\mathrm{R} v 2.8 .1$. The level of significance was set at $P \leq 0.05$.

\section{Results}

\section{Patients}

The analysis included 110 patients. The mean age was 66 years (range 32-84) and 79.1\% were male. All patients had ECOG PS 0 or 1 . The majority were current or former smokers. ADK was the most frequent histological subtype (51.8\%) and SCC was the second most frequent $(40 \%)$. Other subtypes included large-cell carcinoma (4.5\%), mixed adenosquamous carcinoma (1.8\%), and lepidic ADK (1.8\%). The majority of patients had stage I disease (73.6\%). Twenty-six patients $(23.6 \%)$ received adjuvant chemotherapy, 19 for stage II and 7 for stage I disease with $T>4 \mathrm{~cm}$. The mean follow-up was 45 months (range, 7.6-97.7). K-RAS mutations were detected in $19.1 \%$ of all patients and TP53 mutations in $30 \%$. The distribution of TP53 mutations by exon was: 12 mutations in exon 5; six in exon 6; five in exon 7; and ten in exon 8. EGFR mutations were detected in $24.1 \%$ of patients with ADK (Table 1 ).

\section{NKX2-1, miR-365 and miR-33a expression}

NKX2-1 was differentially expressed according to the smoking status of the patient (ANOVA $P=0.03$ ) and 
Table 1 Main patient characteristics

\begin{tabular}{|c|c|c|c|c|}
\hline \multirow[t]{2}{*}{ Characteristics } & \multirow[t]{2}{*}{ Value } & $N=110$ & \multirow{2}{*}{$\begin{array}{l}\text { OS } \\
p \text {-value }\end{array}$} & \multirow{2}{*}{$\begin{array}{l}\text { NKX2-1 } \\
p \text {-value }\end{array}$} \\
\hline & & $N(\%)$ & & \\
\hline \multirow[t]{2}{*}{ Sex } & Male & $87(79.1)$ & \multirow[t]{2}{*}{0.019} & \multirow[t]{2}{*}{0.196} \\
\hline & Female & $23(20.9)$ & & \\
\hline \multirow[t]{3}{*}{ Age, yrs } & Mean (Range) & $66.1(32-84)$ & \multirow[t]{3}{*}{0.018} & \multirow[t]{3}{*}{0.181} \\
\hline & $<=65$ & $51(46.4)$ & & \\
\hline & $>65$ & $59(53.6)$ & & \\
\hline \multirow[t]{2}{*}{ ECOG PS } & 0 & $20(18.2)$ & \multirow[t]{2}{*}{0.067} & \multirow[t]{2}{*}{0.109} \\
\hline & 1 & $90(81.8)$ & & \\
\hline \multirow{2}{*}{ Stage } & । & 81 (73.6) & \multirow[t]{2}{*}{0.334} & \multirow[t]{2}{*}{0.429} \\
\hline & $\|$ & $29(26.4)$ & & \\
\hline \multirow[t]{5}{*}{ Histology } & ADK & $57(51.8)$ & \multirow[t]{5}{*}{0.325} & \multirow[t]{5}{*}{$\begin{array}{l}p< \\
0.001\end{array}$} \\
\hline & SCC & $44(40)$ & & \\
\hline & $\begin{array}{l}\text { Large-cell } \\
\text { Carcinoma }\end{array}$ & $5(4.5)$ & & \\
\hline & Lepidic ADK & $2(1.8)$ & & \\
\hline & $\begin{array}{l}\text { Mixed } \\
\text { adenosquamous }\end{array}$ & $2(1.8)$ & & \\
\hline \multirow[t]{3}{*}{ Type of surgery } & $\begin{array}{l}\text { Lobectomy/ } \\
\text { Bilobectomy }\end{array}$ & $94(85.5)$ & \multirow[t]{3}{*}{0.973} & \multirow[t]{3}{*}{-} \\
\hline & Pneumonectomy & $5(8.1)$ & & \\
\hline & Atypical Resection & $7(6.4)$ & & \\
\hline \multirow[t]{3}{*}{ Smoking history } & Current Smoker & $40(36.3)$ & \multirow[t]{3}{*}{0.075} & \multirow[t]{3}{*}{0.025} \\
\hline & Former Smoker & $58(52.7)$ & & \\
\hline & Never smoker & $12(10.9)$ & & \\
\hline \multirow[t]{2}{*}{ Adjuvant treatment } & Yes & $26(23.6)$ & \multirow[t]{2}{*}{0.663} & \multirow[t]{2}{*}{-} \\
\hline & No & $84(76.4)$ & & \\
\hline \multirow[t]{2}{*}{ Relapse } & No & $76(69.1)$ & - & 0.794 \\
\hline & Yes & $34(30.9)$ & & \\
\hline Emphysema & Yes & $54(49.1)$ & 0.223 & 0.389 \\
\hline & No & $49(44.5)$ & & \\
\hline & Unknown & $7(6.4)$ & & \\
\hline COPD & Yes & $71(64.5)$ & 0.574 & 0.127 \\
\hline & No & $39(35.5)$ & & \\
\hline DLCO (\%) & Mean (Range) & $73(35-100)$ & - & - \\
\hline Molecular Features & TP53 mutation & 33/104 (30) & 0.680 & 0.001 \\
\hline & KRAS mutation & $\begin{array}{l}21 / 109 \\
(19.1)\end{array}$ & 0.815 & 0.204 \\
\hline & $E_{G F R^{a}}$ & $14 / 58(24.1)$ & 0.109 & 0.696 \\
\hline
\end{tabular}

OS overall survival, ECOG PS Eastern Cooperative Oncology Group performance status, $A D K$ adenocarcinoma, SCC squamous cell carcinoma, COPD chronic obstructive pulmonary disease, DLCO diffusing capacity of the lung for carbon monoxide ${ }^{a}$ EGFR mutational status was assessed only in adenocarcinoma patients

was upregulated in never-smokers compared to current and former smokers $(P=0.025$; Fig. 1a).

NKX2-1 expression was also significantly higher in patients with ADK than in those with squamous cell carcinoma (SCC) $(P<0.001$; Fig. 1b). A random selection of samples with ADK were assessed by IHC for NKX2-1. NKX2-1 expression was higher in ADK patients who were IHC-positive for $\mathrm{NKX} 2-1(P=0.043$; Additional file 1: Figure S1).

Patients harboring TP53 mutations had lower NKX2-1 levels than those with wild-type (WT) TP53 $(P=0.001$; Fig. 1c). ANOVA analysis showed that NKX2-1 was differentially expressed in TP53-mutated patients according to exon location $(P=0.02$; Fig. 1d). No significant differences in NKX2-1 expression were observed according to KRAS or EGFR mutational status. miR-365 expression was significantly lower in ADK than in SCC patients $(P=0.003$; Fig. $1 \mathrm{e})$.

When we assessed the potential correlation between the expression of NKX2-1, miR-365, and miR-33a, expression, we found only a negative correlation between NKX2-1 and miR-365 expression $(\rho=-0.287, P=0.003$; Fig. 1f).

The prognostic value of NKX2-1, miR-365 and miR-33a in early-stage NSCLC

Using the optimal cutoff identified by Maxstat, patients were classified as having high or low NKX2-1 expression. Mean OS in patients with high NKX2-1 expression was 80.8 months (95\% CI 69.6-92), compared to 61.2 months (95\% confidence interval [CI] 51.3-71.1) in those with low NKX2-1 expression ( $P=0.035$; Fig. 2a). In addition, patients with high NKX2-1 expression had longer DFS than those with low expression levels (71.7 vs 52.1 months; $P=0.073$; Additional file 1: Figure S2A) When the analysis was limited to patients with stage I disease, mean OS was 79.7 months (95\% CI 67.1-92.3) in patients with high NKX2-1 expression and 57.0 months (95\% CI 45.2-68.9) in those with low NKX2-1 expression ( $P=0.031$; Fig. $2 \mathrm{~b})$.

Patients with high levels of miR-365 showed a trend toward shorter OS than those with high levels (entire cohort: 60.9 vs 79.2 moths, $P=0.073$; Stage I disease: 58.3 vs 76.6 months, $P=0.118$; Additional file 1: Figure S3). No association between miR-33a and OS was observed.

\section{The prognostic value of NKX2-1 according to TP53, KRAS and EGFR mutational status}

Since NKX2-1 has previously been linked to TP53 [20], KRAS [22] and EGFR [36], we explored its prognostic impact according to the mutational status of these genes in our entire cohort. No significant differences in OS according to NKX2-1 levels were found in patients with TP53, KRAS or EGFR mutations. However, in patients without TP53 mutations, OS for those with high NKX2-1 expression was 80.36 months (95\% CI 68.192.6), compared to 56.4 months (95\% CI 43.3-67.5) for those with low NKX2-1 expression $(P=0.048$; Additional file 1: FigureS4A). In patients without KRAS 

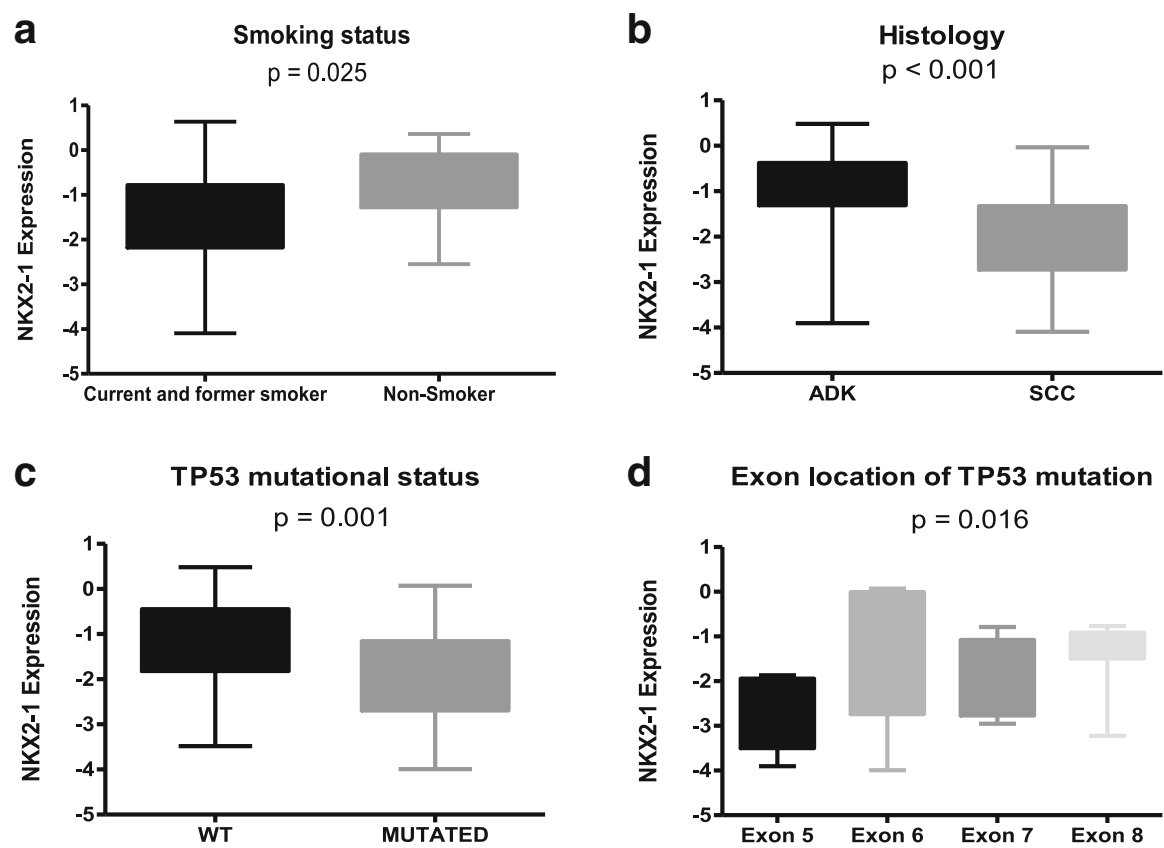

d Exon location of TP53 mutation
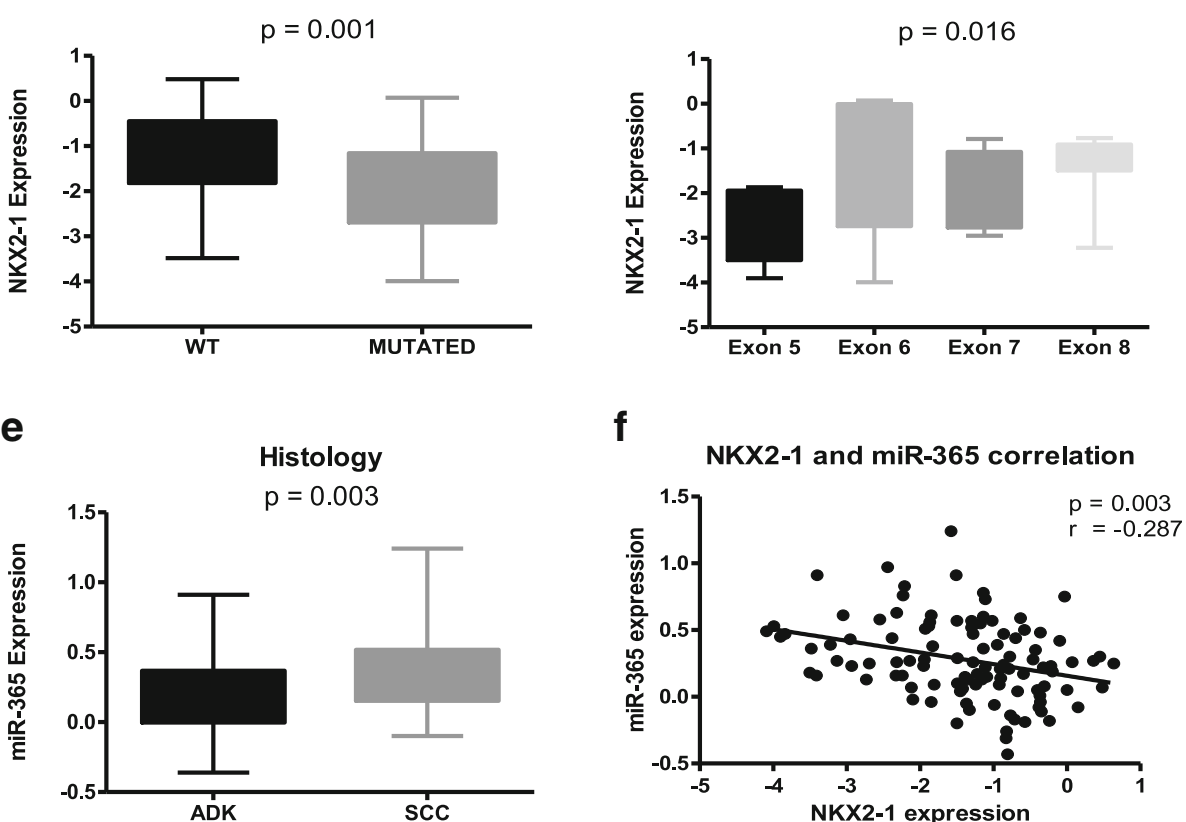

Fig. 1 NKX2-1 and miR-365 expression. NKX2-1 expression according to a smoking status, b histology, c TP53 mutational status, and $\mathbf{d}$ exon location of TP53 mutation. e miR-365 expression according to histology. $\mathbf{f}$ Pearson correlation graph of NKX2-1 and miR-365 expression
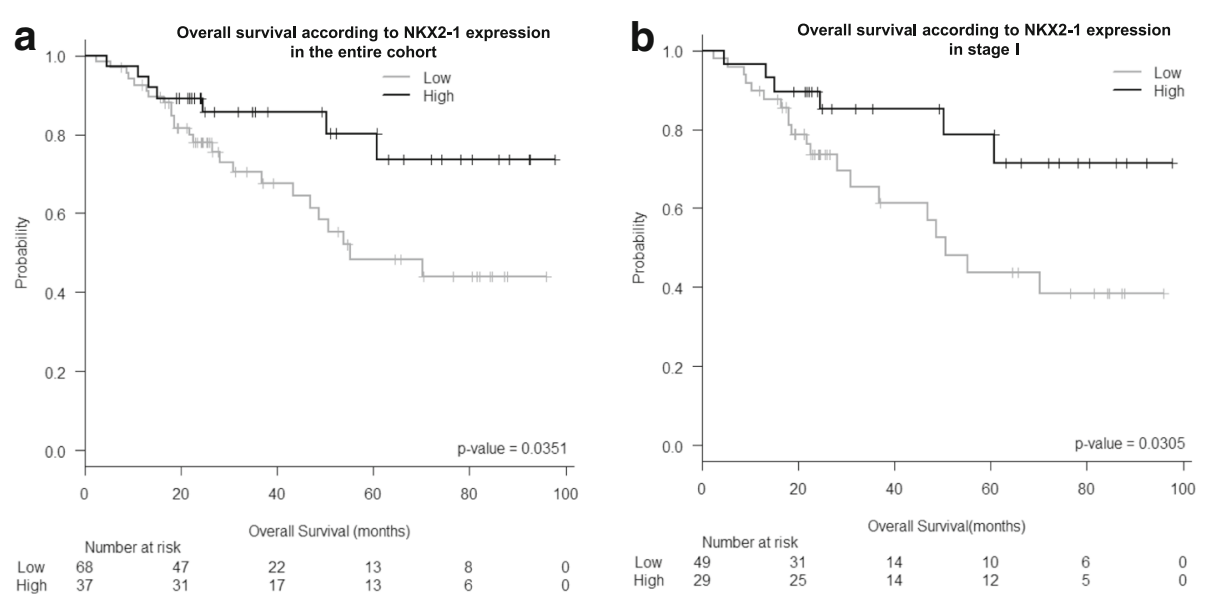

Fig. 2 Kaplan Meier analysis of overall survival according to NKX2-1 expression levels in a the entire cohort and $\mathbf{b}$ patients with stage I disease 
mutations, high NKX2-1 expression was also associated with longer OS. OS for those with high NKX2-1 expression was 79.9 months (95\% CI 68.7-91.1), compared to 60.2 months (95\% CI 49.3-71.1) for those with low NKX2-1 expression ( $P=0.027$; Additional file 1: Figure S4B). These associations were maintained when the analysis was limited to stage I patients (TP53, $P=0.019$; KRAS: $P=0.020$; Additional file 1: FigureS5A-D). In patients without EGFR mutations, there was no association between NKX2-1 expression and OS.

Among patients with neither TP53 nor KRAS mutations, the prognostic impact of NKX2-1 expression was even greater. OS was 77.6 months (95\% CI 66.488.7) for patients with high NKX2-1 expression and 54 months (95\% CI 42.1-65.9) for those with low expression $(P=0.017$; Fig. 3a). DFS was 74.6 months (95\% CI 61.5-87.8) for patients with high NKX2-1 expression and 45.35 months (95\% CI 22-57.7) for those with low expression $(P=0.006$; Additional file 1: FigureS2B). This association was maintained when the analysis was limited to stage I patients in OS (76.9 [95\% CI 65.1-88.7] vs 46.1 [95\% CI 32.3-59.8] months, respectively; $P=0.005$; Fig. $3 \mathrm{~b}$ ), and DFS (73.5 [95\% CI 59.5-87.6] vs 39.6 [95\% CI 26-53.2] months, respectively; $P=0.003$ ).

In the multivariate analysis of all patients without TP53 or KRAS mutations, including age, sex, disease stage, adjuvant therapy, and NKX2-1 expression, NKX2-1 expression emerged as an independent prognostic factor for OS (OR 5.335, 95\% CI 1.32921.421; $P=0.018)$, together with stage $(P=0.018)$ and adjuvant therapy $(P=0.048)$.

In a multivariate analysis NKX2-1 emerges as the only independent prognostic factor for DFS (OR 4.333, 95\% CI $1.466-12.807 ; P=0.008)$.

\section{Discussion}

The potential prognostic impact of NKX2-1 in NSCLC is unclear. Several studies have found an association between low NKX2-1 expression and good prognosis [27$30,37,38]$ while others have reported an association with poor prognosis $[39,40]$ and still others have found no association at all [41-43]. In the present study, we assessed NKX2-1 expression in a cohort of 110 patients with stage I-II NSCLC who had undergone surgical resection as their first therapeutic approach. Our findings indicate that high NKX2-1 expression is associated with longer OS both in the entire cohort $(P=0.035)$ and in the subgroup of stage I patients $(P=0.031)$. Moreover, among patients with neither TP53 nor KRAS mutations, NKX2-1 expression emerged as an independent prognostic factor for OS (OR 5.335; $P=0.018$ ) and DFS (OR 4.333, $P=0.008$ ).

The conflicting findings of previous studies may be due to several factors, including the techniques used for NKX2-1 analysis and the heterogeneity of patient cohorts.

Most of the studies evaluated NKX2-1 expression by Immunohistochemistry [38], a technique that only differentiates between the presence or absence of a protein but cannot quantify the levels of expression, although in some studies [30] the authors use an automated quantitative analysis of protein concentration within subcellular compartments to establish a range of expression. We have evaluated NKX2-1 levels using RT-PCR, which is a highly sensitive technique that can better classify patients with intermediate levels of a gene.

Arguably, the most important difference between studies of the prognostic impact of NKX2-1 lies in the clinical characteristics of the patients included, especially disease stage. A meta-analysis of 2235 patients included
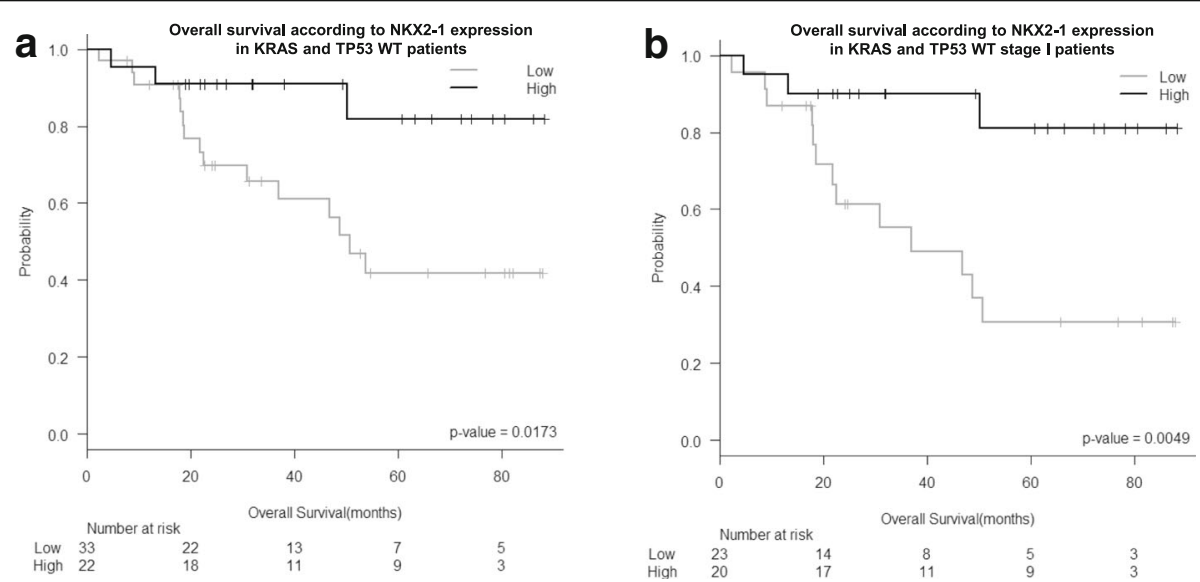

Fig. 3 Kaplan Meier analysis of overall survival according to NKX2-1 expression levels in patients harboring neither TP53 nor KRAS mutations in a the entire cohort and $\mathbf{b}$ patients with stage I disease 
in 17 studies of NKX2-1 found that 937 patients $(80 \%)$ had stage IIIb-IV disease [38]. In fact, the few studies reporting a negative prognostic impact for high NKX2-1 expression were performed in cohorts enriched in stage IIIb patients. Since the inclusion of these patients with locally advanced disease may well confound the identification of prognostic markers, we focused our study on a well-characterized cohort of early-stage patients. Our results are in line with other previous studies [27] where high NKX2-1 expression was related to longer survival. Interestingly, this association was maintained in the subgroup of stage I NSCLC patients, who had not received adjuvant treatment after surgery, suggesting a clear prognostic role for NKX2-1 mRNA expression.

NKX2-1 expression was upregulated in our patients with wild-type TP53. This can be explained by previous findings that NKX2-1 has been linked to regulation of TP53 transcription via LKB1 loss and IKK $\beta$ / NF- $\kappa B$ activation [20, 44].

. NKX2-1 gene amplification displayed a positive correlation with the presence of KRAS mutations; however, its prognostic impact remains controversial. In a Japanese ADK cohort, NKX2-1 amplification was an independent predictor of poor prognosis $[45,46]$ NKX2-1 has also been linked to KRAS in that NKX2-1 gene haploinsufficiency in patients harboring KRAS mutations, with a consequent loss of function of NKX2-1, may promote tumorigenesis in mucinous ADK [47]. In our patients, however, we found no significant differences in NKX2-1 expression according to KRAS status. Nevertheless, when we analyzed the effect of NKX2-1 expression on OS in patient subgroups classified according to TP53 and KRAS mutation status, we found a remarkable impact among patients with both wild-type TP53 and wild-type KRAS. OS in these patients was much longer for patients with high NKX2-1 levels - both in the entire cohort $(P=0.017)$ and in stage I patients $(P=0.005)$. Furthermore, in an exploratory analysis in this subgroup of patients, we found a strong association between high NKX2-1 expression and longer disease-free survival - again both in the entire cohort $(P=0.006)$ and in patients with stage I disease $(P=0.003)$. These findings suggest that NKX2-1 functions are linked to the normal functioning of TP53 and KRAS and that mutations in these genes influence the prognostic impact of NKX2-1 expression.

As expected, NKX2-1 expression in our cohort was higher in ADK than in SCC patients, although high NKX2-1 expression has previously been described in SCC as well [48]. Moreover, we observed an inverse correlation between smoking habit and NKX2-1 levels that is in line with previous reports $[49,50]$, suggesting that NKX2-1 downregulation could be related to smoking habits.
The underlying mechanism of NKX2-1 as a tumor suppressor is not fully understood but we speculated that it might be linked to its associated miRNAs, miR365 and miR-33a. We found a negative correlation between miR-365 and NKX2-1 expression, indicating that miR-365 directly regulates NKX2-1. We also observed an inverse relation between miR-365 and NKX2-1 expression in ADK vs SCC, where miR-365 expression was lower in ADK patients while NKX2-1 expression was higher. Moreover, patients with high levels of miR-365 showed a trend towards shorter OS $(P=0.073)$. Taken together, these findings provide further evidence for a regulatory role of miR-365 over NKX2-1. In contrast, no significant correlation between NKX2-1 and miR33a was observed, suggesting that factors other than NKX2-1 are involved in the regulation of miR-33a.

\section{Conclusions}

The present study confirms a prognostic role for NKX2-1 in early-stage resected NSCLC patients, particularly in those harboring neither TP53 nor KRAS mutations. NKX2-1 expression may thus prove useful for the risk stratification of early-stage NSCLC patients and could be considered when deciding on adjuvant therapy strategies.

\section{Additional file}

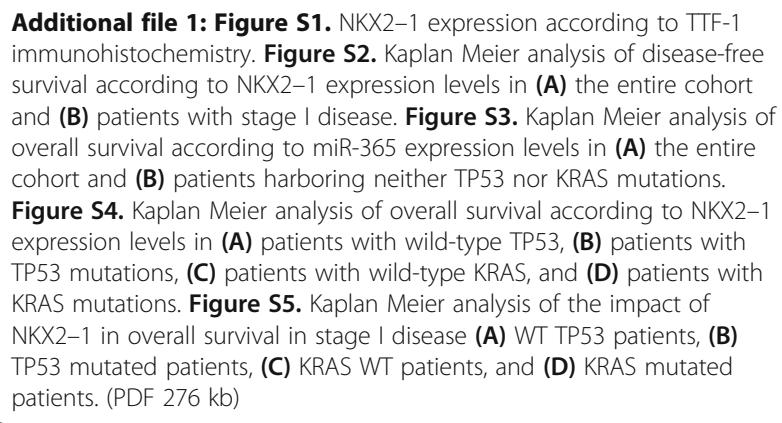

\section{Abbreviations}

ADK: Adenocarcinoma; Cl: Confidence interval; COPD: Chronic obstructive pulmonary disease; DFS: Disease free survival; ECOG: Eastern Cooperative Oncology Group; EMT: Epithelial mesenchymal transition; miRNA: microRNA; NSCLC: Non-small-cell lung cancer; OS: Overall survival; PS: Performance status; SCC: Squamous cell carcinoma; UTR: Untranslated region

\section{Acknowledgements}

Not applicable

\section{Funding}

This work was supported by grants from Hospital Clínic de Barcelona [Premi Fi de Residencia "Emili Letang"- Jorge Moisés], Mutual Médica [Segundo Accésit 2015- Jorge Moisés] and Sociedad Española de Neumología y Cirugía Torácica (SEPAR) [Beca becario 2015, Jorge Moisés], SDCSD from the Universitat de Barcelona and Instituto de Salud Carlos III (FIS 12/405). Sandra Santasusagna and Joan Josep Castellano are APIF fellows of the Universitat de Barcelona. None of the funding bodies had any role in the design of the study and collection, analysis, and interpretation of data, or in writing the manuscript. 


\section{Availability of data and materials}

The datasets used during the current study are available for review upon request at the site of study.

\section{Authors' contributions}

JM, SS, JJC, CM, SM performed the research and acquired laboratory data; JM, AN, RM, MM conceived and designed the research; NV, LM, JO, RM selected cases generated clinical database and analyzed the clinical data; JR and AS provided samples, performed histopathological review and immunohistochemistry analysis; JM, AN, MM, RM drafted the manuscript; SS, JJC, CM, SM, NV, LM, JO, AS, JR revised the article critically for important intellectual content. All authors approved the final version of the manuscript. All authors agree to be accountable for all aspects of the work in ensuring that questions related to the accuracy or integrity of any part of the work are appropriately investigated and resolved.

\section{Ethics approval and consent to participate}

Approval for the study under the registry HCP 2015/0477 was obtained from the Clinical Research Ethics Committee of the Hospital Clínic de Barcelona, and written informed consent was obtained from each participant in accordance with the Declaration of Helsinki.

\section{Consent for publication}

Not applicable

\section{Competing interests}

The authors declare that they have no competing interests.

\section{Publisher's Note}

Springer Nature remains neutral with regard to jurisdictional claims in published maps and institutional affiliations.

\section{Author details}

'Department of Pneumology, Institut Clínic Respiratori (ICR), Hospital Clínic de Barcelona, University of Barcelona, IDIBAPS, CIBER de Enfermedades Respiratorias (CIBERES), Barcelona, Spain. ${ }^{2}$ Molecular Oncology and Embryology Laboratory, Human Anatomy Unit, School of Medicine, University of Barcelona, IDIBAPS, Casanova 143, 08036 Barcelona, Spain. ${ }^{3}$ Department of Medical Oncology, Institut Clínic de Malalties Hematològicas i Oncològiques (ICMHO), Hospital Clínic de Barcelona, University of Barcelona, IDIBAPS, Barcelona, Spain. ${ }^{4}$ Department of Thoracic Surgery, Institut Clínic Respiratori (ICT), Hospital Clínic de Barcelona, University of Barcelona, Barcelona, Spain. ${ }^{5}$ Department of Pathology, Centre de Diagnòstic Biomèdic (CDB), Hospital Clínic de Barcelona, University of Barcelona, IDIBAPS, CIBERES, Barcelona, Spain

Received: 16 July 2017 Accepted: 29 November 2017

Published online: 13 December 2017

\section{References}

1. Torre LA, Bray F, Siegel RL, Ferlay J, Lortet-Tieulent J, Jemal A. Global cancer statistics, 2012. CA Cancer J Clin. 2015;65:87-108.

2. Siegel RL, Miller KD, Jemal A. Cancer statistics, 2017. CA Cancer J Clin. 2017:67:7-30.

3. Ferlay J, Steliarova-Foucher E, Lortet-Tieulent J, Rosso S, Coebergh JWW Comber $\mathrm{H}$, et al. Cancer incidence and mortality patterns in Europe: estimates for 40 countries in 2012. Eur J Cancer. 2013:49:1374-403.

4. Chen Z, Fillmore CM, Hammerman PS, Kim CF, Wong K-K. Non-small-cell lung cancers: a heterogeneous set of diseases. Nat Rev Cancer. 2014; 14:535-46

5. Uramoto H, Tanaka F. Recurrence after surgery in patients with NSCLC. Transl Lung Cancer Res. 2014;3:242-9.

6. Stanfel MN, Moses KA, Schwartz RJ, Zimmer WE. Regulation of organ development by the NKX-homeodomain factors: an NKX code. Cell Mol Biol (Noisy-le-grand). 2005;Suppl 51:OL785-99.

7. Herriges M, Morrisey EE. Lung development: orchestrating the generation and regeneration of a complex organ. Development. 2014;141:502-13.

8. Bruno MD, Bohinski RJ, Huelsman KM, Whitsett JA, Korfhagen TR. Lung cell-specific expression of the murine surfactant protein a (SP-A) gene is mediated by interactions between the SP-A promoter and thyroid transcription factor-1. J Biol Chem. 1995;270:6531-6.
9. Bohinski RJ, Di Lauro R, Whitsett JA. The lung-specific surfactant protein B gene promoter is a target for thyroid transcription factor 1 and hepatocyte nuclear factor 3 , indicating common factors for organ-specific gene expression along the foregut axis. Mol Cell Biol. 1994;14:5671-81.

10. Kelly SE, Bachurski CJ, Burhans MS, Glasser SW. Transcription of the lungspecific surfactant protein $C$ gene is mediated by thyroid transcription factor 1. J Biol Chem. 1996;271:6881-8.

11. Toonen RF, Gowan S, Bingle CD. The lung enriched transcription factor TTF-1 and the ubiquitously expressed proteins Sp1 and Sp3 interact with elements located in the minimal promoter of the rat Clara cell secretory protein gene. Biochem J. 1996;316(Pt 2):467-73.

12. Ramirez MI, Rishi AK, Cao YX, Williams MC. TGT3, thyroid transcription factor I, and Sp1 elements regulate transcriptional activity of the 1.3-kilobase pair promoter of T1alpha, a lung alveolar type I cell gene. J Biol Chem. 1997:272:26285-94.

13. Travis WD, Brambilla E, Noguchi M, Nicholson AG, Geisinger KR, Yatabe $Y$, et al. International association for the study of lung cancer/american thoracic society/european respiratory society international multidisciplinary classification of lung adenocarcinoma. J Thorac Oncol. 2011;6:244-85.

14. International Association for the Study of Lung Cancer/American Thoracic Society/European Respiratory Society International Multidisciplinary Classification of Lung Adenocarcinoma. 2011;1-42.

15. Yatabe Y, Mitsudomi T, Takahashi T. TTF-1 expression in pulmonary adenocarcinomas. Am J Surg Pathol. 2002;26:767-73.

16. Snyder EL, Watanabe H, Magendantz M, Hoersch S, Chen TA, Wang DG, et al. Nkx2-1 represses a latent gastric differentiation program in lung adenocarcinoma. Mol Cell. 2013;50:185-99.

17. Runkle EA, Rice SJ, Qi J, Masser D, Antonetti DA, Winslow MM, et al. Occludin is a direct target of thyroid transcription Factor-1 (TTF-1/NKX2-1). J Biol Chem. 2012:287:28790-801.

18. Saito RA, Watabe T, Horiguchi K, Kohyama T, Saitoh M, Nagase T, et al. Thyroid transcription Factor-1 inhibits transforming growth factor-mediated epithelial-to-mesenchymal transition in lung adenocarcinoma cells. Cancer Res. 2009;69:2783-91.

19. Hosono Y, Yamaguchi T, Mizutani E, Yanagisawa K, Arima C, Tomida S, et al. MYBPH, a transcriptional target of TTF-1, inhibits ROCK1, and reduces cell motility and metastasis. EMBO J. 2011;31:481-93.

20. Chen P-M, T-C W, Cheng Y-W, Chen C-Y, Lee H. NKX2-1-mediated p53 expression modulates lung adenocarcinoma progression via modulating IKKß/NF-KB activation. Oncotarget. 2015;6:14274-89.

21. Chen P-M, T-C W, Wang Y-C, Cheng Y-W, Sheu G-T, Chen C-Y, et al. Activation of NF-KB by SOD2 promotes the aggressiveness of lung adenocarcinoma by modulating NKX2-1-mediated IKK 3 expression. Carcinogenesis. 2013;34:2655-63.

22. Maeda Y, Tsuchiya T, Hao H, Tompkins DH, Xu Y, Mucenski ML, et al. KrasG12D and NkX2-1 haploinsufficiency induce mucinous adenocarcinoma of the lung. J Clin Invest. 2012:122:4388-400.

23. Bartel DP. MicroRNAs: genomics, biogenesis, mechanism, and function. Cell. 2004;116:281-97.

24. Qi J, Rice SJ, Salzberg AC, Runkle EA, Liao J, Zander DS, et al. MiR-365 regulates lung cancer and developmental gene thyroid transcription factor 1. Cell Cycle. 2012;11:177-86.

25. Rice SJ, Lai S-C, Wood LW, Helsley KR, Runkle EA, Winslow MM, et al. MicroRNA-33a mediates the regulation of high mobility group AT-hook 2 gene (HMGA2) by thyroid transcription factor 1 (TTF-1/NKX2-1). J Biol Chem 2013;288:16348-60.

26. Yang L, Yang J, Li J, Shen X, Le Y, Zhou C, et al. MircoRNA-33a inhibits epithelial-to-mesenchymal transition and metastasis and could be a prognostic marker in non-small cell lung cancer. Sci Rep. 2015;5:13677-89.

27. Zhang Y, Wang R, Li Y, Pan Y, Hu H, Zhang Y, et al. Negative thyroid transcription factor 1 expression defines an unfavorable subgroup of lung adenocarcinomas. J Thorac Oncol. 2015;10:1444-50.

28. Barlési F, Pinot D, LeGoffic A, Doddoli C, Chetaille B, Torre J-P, et al. Positive thyroid transcription factor 1 staining strongly correlates with survival of patients with adenocarcinoma of the lung. Br J Cancer. 2005;93:450-2.

29. Berghmans T, Paesmans M, Mascaux C, Martin B, Meert A-P, Haller A, et al. Thyroid transcription factor $1-a$ new prognostic factor in lung cancer: a meta-analysis. Ann Oncol. 2006;17:1673-6.

30. Anagnostou VK, Syrigos KN, Bepler G, Homer RJ, Rimm DL. Thyroid transcription factor 1 is an independent prognostic factor for patients with stage I lung adenocarcinoma. J Clin Oncol. 2009;27:271-8. 
31. Shah L, Walter KL, Borczuk AC, Kawut SM, Sonett JR, Gorenstein LA, et al. Expression of syndecan-1 and expression of epidermal growth factor receptor are associated with survival in patients with nonsmall cell lung carcinoma. Cancer. 2004;101:1632-8.

32. Goldstraw P, Crowley J, Chansky K, Giroux DJ, Groome PA, Rami Porta R, et al. The IASLC lung cancer staging project: proposals for the revision of the TNM stage groupings in the forthcoming (seventh) edition of the TNM classification of malignant tumours. J Thorac Oncol. 2007;2:706-14.

33. Gallardo E, Navarro A, Vinolas N, Marrades RM, Diaz T, Gel B, et al. miR-34a as a prognostic marker of relapse in surgically resected non-small-cell lung cancer. Carcinogenesis. 2009;30:1903-9.

34. Peltier HJ, Latham GJ. Normalization of microRNA expression levels in quantitative RT-PCR assays: identification of suitable reference RNA targets in normal and cancerous human solid tissues. RNA. 2008;14:844-52.

35. Hothorn T, Lausen B. On the exact distribution of maximally selected rank statistics. Comput Stat Data Anal. 2003:43:121-37.

36. Clarke N, Biscocho J, Kwei KA, Davidson JM, Sridhar S, Gong X, et al. Integrative genomics implicates EGFR as a downstream mediator in NKX2-1 amplified non-small cell lung cancer. Chi J-TA. PLoS One. 2015;10:e0142061-17.

37. Zhan P, Qian Q, Wan B, Yan TD, Prognostic YL-K. Value of TTF-1 expression in patients with non-small cell lung cancer: a meta-analysis. Transl Cancer Res. 2013:2:1-8.

38. Qian H-H, T-S X, Cai X-Q, Ji T-L, Guo H-X. Prognostic value of TTF-1 expression in patients with non-small cell lung cancer: a meta-analysis. Clin Chim Acta. 2015;451:208-14.

39. Puglisi F, Barbone F, Damante G, Bruckbauer M, Di Lauro V, Beltrami CA, et al. Prognostic value of thyroid transcription factor-1 in primary, resected, non-small cell lung carcinoma. Mod Pathol. 1999;12:318-24.

40. Sun R, Liu Z, Ma G, Lv W, Zhao X, Lei G, et al. Associations of deregulation of mir-365 and its target mRNA TTF-1 and survival in patients with NSCLC. Int J Clin Exp Pathol. 2015;8:2392-9.

41. Myong N-H. Thyroid transcription factor-1 (TTF-1) expression in human lung carcinomas: its prognostic implication and relationship with wxpressions of p53 and Ki-67 proteins. J Korean Med Sci. 2003;18:494-500.

42. Pelosi G, Fraggetta F, Pasini F, Maisonneuve P, Sonzogni A, lannucci A, et al. Immunoreactivity for thyroid transcription factor-1 in stage I non-small cell carcinomas of the lung. Am J Surg Pathol. 2001:25:363-72.

43. Stenhouse G, Fyfe N, King G, Chapman A, Kerr KM. Thyroid transcription factor 1 in pulmonary adenocarcinoma. J Clin Pathol. 2004;57:383-7.

44. Tsai L-H, Chen P-M, Cheng Y-W, Chen C-Y, Sheu G-T, T-C W, et al. LKB1 loss by alteration of the NKX2-1/p53 pathway promotes tumor malignancy and predicts poor survival and relapse in lung adenocarcinomas. Oncogene. 2013;33:3851-60

45. Inoue $Y$, Shun M, Nobuya K, Tomoaki K, Hiroki M, Akikazu K, et al. Clinicopathological and survival analysis of Japanese patients with resected non-small-cell lung cancer harboring NKX2-1, SETDB1, MET, HER2, SOX2, FGFR1, or PIK3CA gene amplification. J Thorac Oncol. 2015;10:1590-600.

46. Yoshimura K, Inoue Y, Mori K, Iwashita Y, Kahyo T, Kawase A, et al. Distinct prognostic roles and heterogeneity of TTF1 copy number and TTF1 protein expression in non-small cell lung cancer. Genes Chromosome Cancer. 2017;56:570-81.

47. David H Hwang MD, Lynette M Sholl MD, Vanesa Rojas-Rudilla MP, Dimity L Hall BS, Priyanka Shivdasani MS, Elizabeth P Garcia PD, et al. KRAS and NKX2-1 mutations in invasive mucinous adenocarcinoma of the lung. J Thorac Oncol. 2016;11:496-503.

48. Tan D, Li Q, Deeb G, Ramnath N, Slocum HK, Brooks J, et al. Thyroid transcription factor-1 expression prevalence and its clinical implications in non-small cell lung cancer: a high-throughput tissue microarray and immunohistochemistry study. Human Pathol. 2003;34:597-604.

49. Nagashio R, Ueda J, Ryuge S, Nakashima H, Jiang S-X, Kobayashi M, et al. Diagnostic and prognostic significances of MUC5B and TTF-1 expressions in resected non-small cell lung cancer. Sci Rep. 2015;5:8649-7.

50. Shanzhi W, Yiping $H$, Ling $H$, Jianming Z, Qiang $L$. The relationship between TTF-1 expression and EGFR mutations in lung adenocarcinomas. PLOS ONE. 2014;9:e95479-6.

\section{Submit your next manuscript to BioMed Central and we will help you at every step:}

- We accept pre-submission inquiries

- Our selector tool helps you to find the most relevant journal

- We provide round the clock customer support

- Convenient online submission

- Thorough peer review

- Inclusion in PubMed and all major indexing services

- Maximum visibility for your research

Submit your manuscript at www.biomedcentral.com/submit
Biomed Central 